Running head: Teachers' attitudes towards inclusion: questionnaire review

\title{
Teachers' attitudes towards inclusive education: A critical review of published questionnaires
}

Donna L. Ewing, $\mathrm{PhD}^{1 *}$, Jeremy J. Monsen, $\mathrm{PhD}^{2}$ and Stephan Kielblock, $\mathrm{MA}^{3,4}$

${ }^{1}$ School of Applied Social Sciences, Mayfield House, University of Brighton, Falmer, BN1 9PH, UK (email: d.ewing@ brighton.ac.uk; tel: 01273 643487)

${ }^{2}$ Tri-borough Educational Psychology Service (Hammersmith \& Fulham, Kensington \& Chelsea, and Westminster), Education Services, 2nd Floor Green Zone, Royal Borough of Kensington and Chelsea Town Hall, Hornton Street, London W8 7NX, UK (email: jeremymonsen@hotmail.co.uk)

${ }^{3}$ Justus Liebig University Giessen, Department of Education, Karl-Gloeckner-Strasse 21B, 35394 Giessen, Germany (email: Stephan.Kielblock@erziehung.uni-giessen.de)

${ }^{4}$ Macquarie University, Department of Educational Studies, Sydney, NSW 2109, Australia

Word Count (excluding abstract and references): 5645

*Requests for reprints should be addressed to Dr Donna Ewing, School of Applied Social Sciences, Mayfield House, University of Brighton, Falmer, BN1 9PH, UK (email: d.ewing@brighton.ac.uk) 


\begin{abstract}
Teacher attitudes towards inclusive education affect its successful implementation within mainstream schools. This paper reviews nine questionnaires which capture primary school teachers' attitudes towards inclusion, with the aim to support researchers in selecting the most appropriate measure according to the purpose of their study. Most of the reviewed questionnaires showed acceptable reliability and validity. The Multidimensional Attitudes toward Inclusive Education Scale (MATIES) and the Sentiments, Attitudes, and Concerns about Inclusive Education Revised Scale (SACIE-R) were the only questionnaires with adequate psychometric properties which addressed the affective, cognitive and behavioural components of teachers' attitudes. As another psychometrically sound scale, the Teachers' Attitude towards Inclusion Scale (TAIS) was found to use more up-to-date terminology and suitably addressed the cognitive and behavioural components. This paper provides a useful resource to facilitate the appropriate selection of questionnaires that measure teachers' attitudes towards inclusion.
\end{abstract}

Keywords: critical review; inclusive education; teacher attitudes; scales 


\section{Introduction}

Inclusive education can be defined as the inclusion of all children and young people regardless of any individual differences, including race, ethnicity, disability, gender, sexual orientation, language, or socioeconomic status (Polat, 2011). For the purpose of this review, 'inclusive education' is used to describe the more specific inclusion of children and young people with special educational needs (SEN) [also known as Additional Support Needs (ASN), special educational needs and disabilities (SEND), learning difficulties (LD), or special needs $(\mathrm{SN})]$ within the mainstream classroom. This definition is widely used within the special education literature (Artiles, Kozleski, Dorn, \& Christensen, 2006) and underpins the questionnaires reviewed in this paper. Terminology for inclusive education has been adapted over the years to represent the change from the segregation of children with SEN from mainstream schooling (such as in special education), to the integration of children with SEN within mainstream schools, and to the full inclusion of children with SEN within mainstream schools, where values, attitudes, policies and practices within the school fully facilitate children's participation within classroom and wider school and community activities (Polat, 2011).

Over recent years, there has been a substantial rise in the number of children identified as having complex needs, such as profound and multiple learning difficulties, severe learning difficulties, autistic spectrum disorders and multi-sensory impairments. Whilst in 2004 the number of children with complex needs was approximately 49,300, this figure has almost doubled to 73,000 over the last decade or so (Pinney, 2016). It is possible that the rise in the number of students with complex needs may have an impact on teachers' attitudes towards the inclusion of these students, with teachers possibly feeling underresourced to provide support for these children (e.g. Goodman \& Burton, 2010). In addition, the rate of permanent exclusions from schools has increased over the last few years, with 
almost half of both permanent and fixed period exclusions in 2015/16 being for children with SEN (Department for Education, 2017), which may be reflective of the difficulties that teachers have for supporting such large numbers of children with SEN within the mainstream classroom. Understanding reasons, such as these, for teachers' positive or negative attitudes towards inclusion is important to enable educational psychologists to support teachers in implementing classrooms that are conducive to inclusion education. This review considers the available questionnaires that capture teachers' attitudes towards inclusion, with the aim of identifying suitable measures for educational psychologists to use in understanding teachers' attitudes and to support them in teaching children with SEN.

\section{Enabling Full Inclusion}

In their review of research considering barriers to inclusive practice, Artiles et al. (2006) discuss the difficulties that teachers face in implementing fully inclusive classrooms within political and organisational cultures that are not conducive to the full inclusion of all students. By implication, the full inclusion of all students may require the transformation of school cultures to ensure that all students are present and accepted by others within the school, and to ensure that student participation and achievement is maximised for all. Indeed, Janney and Snell (2006) suggest that a range of cultural elements within the school need to be considered to facilitate effective inclusive education. These include whether there is an inclusive culture within the school, whether positive relationships are facilitated between students with and without SEN, and whether teaching materials and curricula are suitably adapted for a range of learning needs. For instance, curriculum adaptations can be made at an individual level for children with SEN, such as through setting individualised learning goals and/or providing additional support to the students where necessary (Janney \& Snell, 2006). 
To implement such changes requires endorsement of inclusive education policies by both teachers and schools. Indeed, in a questionnaire-based study investigating the relation between teachers' attitudes towards children with SEN and their behavioural intentions, individual teachers' beliefs about inclusive education, as well as their perceptions about their ability to control the inclusive nature of their classroom, were found to be significant predictors of their intentions to promote the full inclusion of children with SEN within their classroom (MacFarlane \& Woolfson, 2013). Given that beliefs about inclusion predict teachers' intentions to fully include children with SEN, it is possible that successful inclusion may also rely on teachers' and school headteachers' acceptance of inclusive policy and their willingness to make necessary changes to enable inclusion within mainstream schools.

\section{Teacher Attitudes}

Teacher attitudes affect whether or not a classroom learning environment is conducive to inclusive education (Monsen, Ewing, \& Kwoka, 2014). However, teachers' attitudes towards the inclusion of children and young people with SEN vary greatly. For instance, some teachers are willing to include children with SEN within the mainstream classroom when adequate support is directly available to them, while other teachers believe that the inclusion of children with SEN may be detrimental to the education of the rest of the class (Grieve, 2009). Others feel that children and young people with SEN would be better provided for within special schools where it is supposed that they receive a higher quality and level of support than that provided within mainstream schools (Grieve, 2009).

A range of factors affect the attitudes that teachers hold about the concept and practice of inclusive education, such as perceived availability and quality of resources and support, teachers' perceptions of their own competence in facilitating an inclusive classroom learning environment, and the behaviour of pupils with SEN (Forlin, Keen, \& Barrett, 2008; Goodman 
\& Burton, 2010; Monsen et al., 2014). For instance, teachers expressed concerns about short attention spans, limited speech, language and communication skills, and/or inappropriate social skills of pupils with SEN when implementing inclusive education (Forlin et al., 2008). In addition, teachers were concerned about their competency to include children with SEN within their classrooms, with some teachers feeling insufficiently trained, and expressed difficulty in monitoring other students when attending to pupils with SEN and a reduced ability to teach the whole class as effectively (Forlin et al., 2008). Other barriers identified by teachers include the SEN pupils' lack of social competence or level of disengagement, low academic attainment, inflexible staff attitudes towards adapting teaching approaches, and parental anxiety that their child will not have their needs met (Gibb, Tunbridge, Chua, \& Frederickson, 2007).

Negative attitudes towards inclusion can be associated with less inclusive classroom learning environments, with evidence to suggest that teachers with less positive attitudes toward inclusion (according to self-reports) have pupils who report less satisfaction and cohesiveness within the classroom, and greater friction, competitiveness and difficulty between the pupils (Monsen et al., 2014). On the other hand, effective school and classroom management, an inclusive school culture and ethos, and the availability of an 'Inclusion Team' who could be contacted for guidance on teaching strategies and practices have been found to facilitate inclusive practices (Gibb et al., 2007).

\section{Measuring Teachers Attitudes}

Considering that teachers' attitudes towards inclusion predict whether or not inclusive behaviours are intended and adopted within mainstream classrooms (MacFarlane \& Woolfson, 2013; Monsen et al., 2014), it is important to be able to measure such attitudes towards the inclusion of children with SEN so that any barriers towards the successful 
implementation of inclusive education policies can be identified and addressed. This is particularly important given the research evidence that teachers' attitudes have a significant impact upon whether or not the learning environment is enabling for children and young people with SEN (Monsen et al., 2014; Monsen \& Frederickson, 2004). Indeed, understanding teachers' attitudes towards inclusion is a key initial step in the design and evaluation of initiatives to improve attitudes towards children with SEN (Antonak \& Livneh, 2000) and, by implication, to increase inclusive behaviours (MacFarlane \& Woolfson, 2013) and to develop more inclusive classroom learning environments (Monsen et al., 2014; Monsen \& Frederickson, 2004).

Attitudes towards individuals with SEN are multi-faceted, including separate domains of 'cognition', which reflects what is known about SEN, 'affect' or the emotional reaction to children with SEN, and 'behaviour', which includes either actual or intended behaviours towards children with SEN (Nowicki \& Sandieson, 2002). Given the range of factors that may facilitate or pose constraints towards teachers' positive attitudes about inclusive education, it is important to have robust questionnaires (along with other methodologies) that explore teachers' perceptions about the inclusion of children with SEN within mainstream classrooms. Indeed, Antonak and Livneh (2000) argue that psychometrically sound instruments are imperative to explore the relationship between attitudes towards individuals with SEN and the full inclusion of these individuals within society. They recommend that rather than develop new scales, existing scales should be refined, revised and updated as necessary, and that multifaceted measures of attitudes that consider cognitive, affective and behavioural components would be preferable to evaluate attitudes towards individuals with SEN (Antonak \& Livneh, 2000).

The current paper reviews questionnaires of teacher attitudes towards inclusion that are currently available for use in primary (or elementary) schools. The aim of this review is 
to provide a useful resource to help researchers and practitioners identify the most appropriate questionnaire to measure teachers' attitudes and to identify, for example, areas of possible training need to develop more positive attitudes, and/or to evaluate the success or otherwise of interventions aimed at developing more inclusive practice.

\section{Method}

\section{Systematic Literature Search}

Questionnaires that measured teachers' attitudes towards inclusive education were identified through a systematic literature search. The search was conducted using PsycInfo, and an additional internet search was conducted for relevant papers. A text search was conducted for keywords using the following search terms (which includes previous terminology to ensure that questionnaires using earlier terms were also identified within the search):

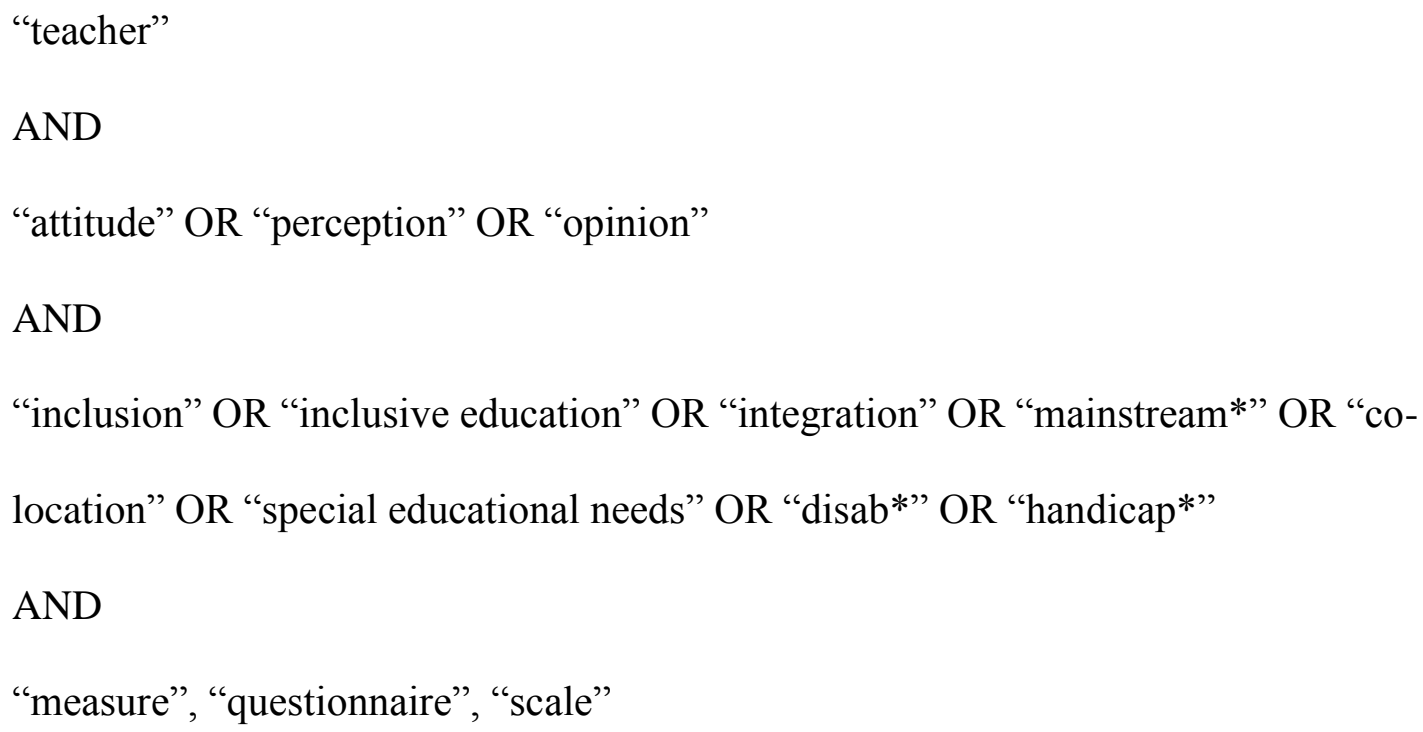

\section{Selection of Papers}

The search identified 1,882 papers to be considered for review. The titles and abstracts of these papers were screened against inclusion and exclusion criteria (see below), prior to consideration of the full-text. The following inclusion criteria were used for the review: 
a) The paper presented the development or use of a new or revised (quantitative) questionnaire that measured teachers' attitudes towards inclusive education for children with SEN.

b) The questionnaire was intended for completion by primary/elementary school teachers.

c) The paper included at least some psychometric properties of the questionnaire.

d) The paper was published between 1995 and 2015 .

e) The paper was published in a peer reviewed journal.

The following exclusion criteria were used for the review:

a) The paper reported no psychometric properties.

b) The questionnaire was aimed at teachers of specific subjects only (e.g., physical education teachers).

c) The questionnaire was solely aimed at preschool, secondary or higher education teachers.

d) The questionnaire focused on one specific learning difficulty/disability.

e) The paper presented a qualitative measure of teachers' attitudes.

f) The paper was not written in English.

\section{INSERT FIGURE 1 HERE}

The titles of the papers were initially screened for eligibility, which resulted in the exclusion of 1,668 studies because they did not address teachers' attitudes towards inclusion (for example, instead focusing on the effectiveness of inclusive education), or were not published in English. Following this stage, 214 papers remained. The abstracts of these papers were checked against the inclusion and exclusion criteria, which resulted in a further 192 papers 
being excluded as they did not present a questionnaire of teachers' attitudes. A more detailed screening against the inclusion and exclusion criteria was conducted using the full-texts for the remaining 25 papers, which resulted in the removal of a further 16 papers. Reasons for removal at this stage included: the paper did not present a new questionnaire, the questionnaire did not assess teachers' attitudes toward inclusion, the questionnaire was intended for preschool teachers or specifically for physical education/music teachers, or the paper was not published in a peer reviewed journal. Nine papers remained for review. Figure 1 shows the flow diagram of the search results.

\section{Data Analysis}

Based on criteria suggested by Fitzpatrick, Davey, Buxton, and Jones (1998) to assess questionnaires, the included questionnaires were judged against the following criteria (see Table 1):

- Reliability and validity: The reproducibility and internal consistency of the questionnaire was considered to assess reliability. Ensuring the reliability of questionnaires is essential in establishing that any changes observed are not due to measuring issues, and good internal consistency suggests that the items are measuring a single attribute (Fitzpatrick et al., 1998), namely, teacher attitudes. The validity of the items used within the questionnaire was assessed according to reports of external validity (generalisability to the wider population), concurrent validity (whether the questionnaires were reflective of other established measures), construct validity (how well the questionnaires measure what they claim to), and face validity (how representative the questionnaire appears). It is important to ensure validity of the questionnaires to establish that they measure that which they aim to measure (Fitzpatrick et al., 1998). 
- Interpretability and feasibility: As recommended by Fitzpatrick et al., (1998), interpretability was assessed according to how meaningful the scores of the questionnaire were according to the purpose of the questionnaire, and feasibility was assessed in terms of ease of administration and processing of the questionnaire.

- Acceptability: This refers to how acceptable respondents find the questionnaire to complete, which includes issues such as respondent burden or refusal to complete the questionnaire. The reviewed questionnaires were considered in terms of how acceptable they were for those completing them as assessed according to the time taken to complete the questionnaire and response rates from teachers recruited to the study (Fitzpatrick et al., 1998).

- Appropriateness: Assessing the appropriateness of a questionnaire includes identifying whether the questionnaire content captures relevant information about the concept under study (Fitzpatrick et al., 1998). As such, questionnaires were firstly considered for appropriateness in terms of the terminology used, and secondly, in terms of addressing each of the three components of teachers' attitudes towards inclusive education: affect (how the teacher feels about including children with SEN within the mainstream class), cognitions (what the teacher thinks about including children with SEN within the mainstream class), and behaviours (what the teacher is willing (or unwilling) to do in implementing inclusive education).

INSERT TABLE 1 HERE 


\section{Results}

\section{Description of Included Questionnaires}

Characteristics of the nine questionnaires that met the inclusion and exclusion criteria are displayed in Table 2. The majority of these questionnaires were developed and administered within English speaking countries $(\mathrm{N}=8)$, although some of these were used in Hong Kong, Singapore and India (for example, Forlin, Earle, Loreman, \& Sharma, 2011; Sharma \& Desai, 2002). One questionnaire was developed and administered in Dutch, although was translated to English for publication (de Boer, Timmerman, Pijl, \& Minnaert, 2012).

Although questionnaires that were specifically targeted at teachers of preschool, secondary school or higher education were excluded from the review, some of the included papers presented questionnaires that were suitable for use across a range of ages. Three were administered to primary (or elementary) school teachers only (de Boer et al., 2012; Monsen, Ewing, \& Boyle, 2015; Sharma \& Desai, 2002), six were administered to both primary and secondary school teachers (Antonak \& Larrivee, 1995; Bailey, 2004; Forlin et al., 2011; Hastings \& Oakford, 2003; Mahat, 2008; Wilczenski, 1995), and two of these were additionally administered to preschool teachers (Bailey, 2004; Forlin et al., 2011). Two of the questionnaires were administered to pre-service teachers (Forlin et al., 2011; Hastings \& Oakford, 2003), while the remainder were administered to practicing teachers. The number of items included in the final version of the questionnaires ranged from 15-30 items, and the Likert ratings for the questionnaires ranged from 4-point to 8-point scales. Most of the scales reflected teachers agreement or disagreement to the items, with the exception of the Concerns about Integrated Education (CIE: Sharma \& Desai, 2002) questionnaire where the Likert scale reflected the level of teachers' concern about each of the questionnaire items.

\section{INSERT TABLE 2 HERE}




\section{Assessment of the Included Questionnaires}

Reliability and validity. The majority of the questionnaires $(77.78 \%)$ showed at least acceptable levels of internal consistency, although the Teacher Questionnaire (de Boer et al., 2012) and the ATIES (Wilczenski, 1995) did not report reliability statistics. Tests of validity were available for the majority of the questionnaires $(88.89 \%$, see Table 1$)$, although there was no report of validity for the IIQ (Hastings \& Oakford, 2003). Generally, only one method of validity was used, with the exception of the MATIES (Mahat, 2008) which demonstrated acceptable content, construct, criterion and convergent validity, and the PATIE (Bailey, 2004) which demonstrated acceptable construct and face validity. Acceptable concurrent validity was reported for the ORI (Antonak \& Larrivee, 1995), acceptable construct validity was reported for the Teacher Questionnaire (de Boer et al., 2012) and the ATIES (Wilczenski, 1995), acceptable content validity was reported for the CIE (Sharma \& Desai, 2002), acceptable convergent validity was reported for the TAIS (Monsen et al., 2015), and acceptable cross-cultural validity was reported for the SACIE-R (Forlin et al., 2011).

Interpretability and feasibility. Each of the questionnaires included in this review used Likert-type scales for teachers' responses to the items, and negative items (where applicable) were reverse-scored so that higher scores indicated more favourable attitudes towards inclusion. The exception was the CIE (Sharma \& Desai, 2002) where a high score indicated greater concerns about inclusion. It was unclear from the papers whether high scores for the PATIE (Bailey, 2004) or the MATIES (Mahat, 2008) indicated more positive or negative attitudes. Given the use of Likert-scales for scoring, and the self-report format, 
the feasibility of administering and processing the questionnaires is comparable across each of those reviewed in this paper, with each being relatively simple to administer and to score.

Acceptability. Out of the reviewed questionnaires, only the ORI (Antonak \& Larrivee, 1995) reported the time required to complete the questionnaire. For the ORI, the authors reported a maximum completion time of 20 minutes. However, all the questionnaires were relatively short, ranging from 15 items for the SACIE-R (Forlin et al., 2011) to 30 items for the TAIS (Monsen et al., 2015; see Table 2). 55.56\% of the reviewed papers reported on response rates, which ranged from 24\% (Teacher Questionnaire: de Boer et al., 2012) to 80\% (CIE: Sharma \& Desai, 2002). Response rates were not reported for the ORI (Antonak \& Larrivee, 1995), the SACIE-R (Forlin et al., 2011), the TAIS (Monsen et al., 2015), and the ATIES (Wilczenski, 1995). With the exception of the CIE (Sharma \& Desai, 2002) which showed response rates of at least $80 \%$, response rates were generally quite low (Teacher Questionnaire: 24\%; PATIE: 47.1\%, MATIES: 53.2\%, and IIQ: 62\%), which may suggest low acceptability of these questionnaires by completers.

Appropriateness. Most of the questionnaires used up-to-date terminology of 'inclusion' and 'special educational needs', rather than earlier terms, such as 'mainstreaming', 'integration', or 'handicapped'. The CIE (Sharma \& Desai, 2002) and the ORI (Antonak \& Larrivee, 1995) use the now out-dated term of 'integration' and, therefore, may be less appropriate for contemporary use. In addition, the use of the term 'disability' within the CIE and the ORI does not encompass the full range of SEN that may be found within inclusive classrooms, such as emotional, behavioural or learning difficulties. Likewise, the PATIE (Bailey, 2004) the SACIE-R (Forlin et al., 2011) and the MATIES (Mahat, 2008) use the term 'disability' for many of the items and so may not always be 
appropriate when considering other types of difficulties. However, although there is a focus on the term 'disability', the PATIE, SACIE-R and MATIES do use alternative terminology for some items which are appropriate for a range of SEN.

The questionnaires included in the review were assessed for appropriateness according to whether they addressed the cognitive, behavioural and affective components of teachers' attitudes towards inclusion. Just three of the questionnaires considered each of these components, which included the Teacher Questionnaire (de Boer et al., 2012), the SACIE-R (Forlin et al., 2011), and the MATIES (Mahat, 2008). While comparable for the cognitive component, these questionnaires each differed in their focus on the behavioural and affective components of teacher attitudes towards inclusion. For instance, the SACIE-R considered teachers' interactions with children with SEN (behavioural) and teachers' concerns about inclusion (affective). On the other hand, the Teacher Questionnaire and the MATIES considered what teachers were willing to do to enhance inclusion within their classroom (behavioural), and considered teachers' feelings about their competence, confidence, frustration, and irritation associated with the inclusion of children with SEN (affective).

All of the questionnaires considered the cognitive component of teachers' attitudes towards inclusive education, which generally captured teachers' perceptions and beliefs about inclusive education and children with SEN. For instance, the ORI (Antonak \& Larrivee, 1995), the PATIE (Bailey, 2004) and the TAIS (Monsen et al., 2015) capture teachers' thoughts about the social, emotional and academic benefits or limitations of including children with SEN within the classroom, implications for managing an inclusive classroom (such as workload), and thoughts about managing the teaching of mixed SEN and non-SEN pupils (including the management of behavioural problems). In addition, the ORI, PATIE and TAIS each touch on teachers' cognitions about training needs and their self-efficacy to 
teach children with SEN. The IIQ (Hastings \& Oakford, 2003) captures teachers' cognitions about disruptions to the school routine and managing the inclusive classroom environment. Likewise, the CIE (Sharma \& Desai, 2002) captures information about teachers' concerns about classroom management, declining academic standards, and the extra input required of teachers. In addition, the CIE captures teachers' concerns about other students' acceptance of students with SEN, as well as concerns about financial resources available to implement inclusive classrooms.

The ATIES (Wilczenski, 1995) and the SACIE-R (Forlin et al., 2011) adopt a different approach for the cognitive component by capturing teachers' attitudes about whether inclusive education should be available for children with particular difficulties. Similarly, the MATIES (Mahat, 2008) captures teachers' beliefs about whether children with SEN should be taught within inclusive classrooms or special education facilities. In addition to this, the MATIES considers teachers' beliefs about academic and social benefits of children with and without SEN being taught in inclusive classrooms or special education facilities.

Less than half of the questionnaires considered the behavioural component (44.44\%). Those that did consider this were the Teacher Questionnaire (de Boer et al., 2012), the SACIE-R (Forlin et al., 2011), the MATIES (Mahat, 2008), and the TAIS (Monsen et al., 2015). These questionnaires captured what the teachers were willing to do to implement inclusive education. For instance, the Teacher Questionnaire and SACIE-R captures information about teachers' willingness to interact with and support children with SEN, while the MATIES considers behavioural intentions of the teacher, such as a willingness to adapt the classroom environment, teaching methods, and the curriculum in order to accommodate the child with SEN within the classroom. The TAIS adopts a different approach and includes a separate section for the behavioural component in which information is captured about how 
willing teachers are to include children with particular difficulties, and considers each of these difficulties across a range of severities.

Just over half of the reviewed questionnaires $(55.56 \%)$ considered the affective component of teachers' attitudes towards inclusive education, including the Teacher Questionnaire (de Boer et al., 2012), SACIE-R (Forlin et al., 2011), IIQ (Hastings \& Oakford, 2003), MATIES (Mahat, 2008), and CIE (Sharma \& Desai, 2002). The Teacher Questionnaire and the MATIES included items capturing teachers' feelings about their competence, frustration, irritation, discomfort, and confidence in including children with SEN within the mainstream class, as well as teachers' feelings about adapting the classroom according to the needs of children with SEN. The SACIE-R addresses teachers' concerns about inclusion, including worries about workload, preparedness to teach children with SEN, and concerns about ensuring all children are given sufficient attention within the class. Similarly, the CIE includes questions about teachers' perceptions about their ability to teach children with SEN, their ability to cope with the needs of children with SEN, and their stress and ability to cope with implementing an inclusive classroom. Lastly, the IIQ considers teachers' feelings of being physically or emotionally drained as a result of implementing inclusive education, including questions about the impact of inclusive education on the extra input required from teachers, as well as stress implications.

\section{Discussion}

Within this paper, the authors reviewed published questionnaires of primary school teachers' attitudes towards inclusion between 1995 and 2015. There were very few published questionnaires designed for this purpose, with only nine questionnaires identified for review. This finding was unexpected given the global emphasis on inclusive education in both policy and practice over the last 30 or so years (Department for Children Schools and Families, 
2010; Department for Education and Skills, 2001, 2003, 2004, 2006; UNESCO, 1994), and with the rise in the number of children with complex needs over recent years (Pinney, 2016). One might expect that new questionnaires would be developed to capture teachers' attitudes towards inclusion based upon the most up-to-date thinking, policies and relevant practices. Indeed, of the questionnaires considered within this review, two were systematically updated and revised from earlier versions. For example, the TAIS (Monsen et al., 2015) and the ORI (Antonak \& Larrivee, 1995) update the well-established Opinions Relative to Mainstreaming (ORM) scale (Larrivee \& Cook, 1979), with the TAIS reflecting the current practice of the 'inclusion' of children with SEN within mainstream schools, rather than the previous emphasis on their 'integration' as in the ORI. The other questionnaires in this review similarly reflect up-to-date terminology, with the exception of the CIE (Sharma \& Desai, 2002) which, like the ORI, uses the term 'integration'. Interestingly, some of the older questionnaires (for example, the ATIES and IIQ) did not use out dated terminology and could still be appropriate for contemporary use. However, caution is required in selecting the PATIE (Bailey, 2004), SACIE-R (Forlin et al., 2011) and the MATIES (Mahat, 2008), in addition to the ORI and CIE, each of which focus on 'disability' rather than SEN and may make these questionnaires less appropriate for establishing teachers' attitudes towards the inclusion of children with behavioural, emotional or learning difficulties rather than physical disabilities.

Due to the exclusion of papers not written in English for this review, the majority of the questionnaires were administered in English-speaking countries. Therefore, it is difficult to determine the usability of these questionnaires when delivered in alternative languages and cultural contexts. The SACIE-R (Forlin et al., 2011) can be commended for being administered and validated for use in a range of countries, including Hong Kong, Singapore, India, Canada, Australia, and the USA. 
All of the papers included within the review reported at least some psychometric properties about the questionnaires. Only two of the studies did not report complete statistics. For instance, no reliability statistics were reported for the Teacher Questionnaire (de Boer et al., 2012). In addition, this questionnaire showed only weak to moderate construct validity. The lack of reliability statistics and the weak construct validity of this questionnaire makes it difficult to recommend it for assessing teachers' attitudes towards inclusive education. The IIQ (Hastings \& Oakford, 2003) was reported to show good internal consistency, but unfortunately no tests of validity were reported. Each of the other questionnaires were able to demonstrate good to excellent internal consistency and acceptable validity. The PATIE (Bailey, 2004) and the MATIES (Mahat, 2008) can be commended for exploring multiple tests of validity, while most of the questionnaires considered only one validity test.

The interpretability and feasibility of the questionnaires was comparable across the reviewed questionnaires. More information about the scoring of the PATIE (Bailey, 2004) and MATIES (Mahat, 2008) would be beneficial to ensure clarity about whether high scores reflect more positive or negative attitudes towards inclusion. Most of the papers reporting on the questionnaires lacked information about the acceptability of the questionnaires, with only one study reporting on completion time, and with only five studies reporting on response rates. It is recommended that future studies presenting questionnaires should ensure that this data is reported. For those studies that did report response rates, relatively low levels were reported, with the exception of the CIE (Sharma \& Desai, 2002) showing evidence of good acceptability, according to response rates of $80 \%$.

All of the questionnaires reviewed in this paper provide appropriate ways for sampling teachers' attitudes towards inclusion. However, the focus of the questionnaires differs greatly, which needs to be taken into account when selecting the most appropriate questionnaire to use for specific purposes and research questions. Whilst the SACIE-R 
(Forlin et al., 2011), the MATIES (Mahat, 2008) and the Teacher Questionnaire (de Boer et al., 2012) considered each of the affective, cognitive and behavioural aspects of teachers' attitudes, the emphasis for each questionnaire was different. For instance, the SACIE-R may be more appropriate when considering teachers' interactions with children with SEN, whereas the MATIES may be more appropriate when considering how teachers implement inclusive practices within their classrooms. The poor psychometric properties of the Teacher Questionnaire, the low response rate and acceptability of the MATIES, the unknown acceptability of the SACIE-R, and the focus on disability rather than SEN for both the MATIES and the SACIE-R, may, none-the-less, limit the usefulness of these questionnaires.

For the majority of the questionnaires reviewed in this paper, the cognitive component of teachers' attitudes towards inclusion was addressed well, considering a range of relevant cognitions about implications for children with SEN and implications for managing an inclusive classroom environment. A few of the questionnaires additionally considered teachers' cognitions about training needs, including the ORI (Antonak \& Larrivee, 1995), PATIE (Bailey, 2004) and TAIS (Monsen et al., 2015). On the other hand, the ATIES (Wilczenski, 1995) and the SACIE-R (Forlin et al., 2011) do not capture teachers' cognitions about inclusive education beyond whether or not they feel that children with these particular difficulties should be included, and so alternative questionnaires may be more suited for capturing the cognitive component of teachers' attitudes. Details for the cognitive component of the Teacher Questionnaire (de Boer et al., 2012) were not provided within the paper and so cannot be commented on. Given the completeness of addressing the cognitive component, the appropriate terminology used, and acceptable psychometric properties, the TAIS may be an appropriate choice for researchers or practitioners seeking to explore teachers' cognitions about teaching children with SEN and implementing inclusive 
classrooms. Where a focus on disability rather than SEN is suitable, the PATIE may be an appropriate alternative.

A further benefit of the TAIS (Monsen et al., 2015) is that it includes a separate section that captures the behavioural component of teachers' attitudes. Unlike the other reviewed questionnaires, the TAIS captures information about the types and severities of SEN that teachers would be willing to include within an inclusive classroom. Therefore, the TAIS may be a particularly useful resource for researchers or practitioners who seek to identify the types of SEN that may prevent teachers from endorsing positive attitudes towards inclusion, which may be the first step in identifying training needs for teachers to enable them to feel more confident in including children with such difficulties. Alternatively, the MATIES (Mahat, 2008) may be a useful resource to consider the behavioural intentions of teachers in terms of the types of adaptations that teachers are willing to make to their classroom and teaching practices.

For the questionnaires that addressed the affective component, the MATIES (Mahat, 2008) and the Teacher Questionnaire (de Boer et al., 2012) focused on teacher feelings about the practice of inclusive education, while the SACIE-R (Forlin et al., 2011), CIE (Sharma \& Desai, 2002) and IIQ (Hastings \& Oakford, 2003) focused on concerns in relation to the practice of inclusive education. For this component, it is worth considering which of these approaches is most appropriate for use on a case-by-case basis. However, it is worth noting that there is no clear separation between the cognitive and affective components for the CIE and IIQ, which may limit the usefulness of these questionnaires.

\section{Conclusion}

This review provides a resource for identifying suitable measures for assessing teachers' attitudes towards inclusive education, which may be useful within educational psychology 
practice to explore potential barriers to inclusive education, to identify particular training needs for more successful implementation of inclusive policy, or to evaluate change in teacher attitudes. Whilst the Teacher Questionnaire (de Boer et al., 2012), the MATIES (Mahat, 2008), and the SACIE-R (Forlin et al., 2011) address each of the affective, cognitive, and behavioural components of teachers' attitudes, it is acknowledged that these may not always be the most appropriate to use. Indeed, the response rate for the Teacher Questionnaire (de Boer et al., 2012) was very poor, suggesting low acceptability of the questionnaire by users. In addition, the psychometric properties of the Teacher Questionnaire were either missing or poor, and so the reliability and validity of this scale cannot be affirmed. Likewise, response rates for the MATIES were fairly low, and were not reported for the SACIE-R, and terminology for both the MATIES and the SACIE-R had a greater focus on disabilities rather than SEN in general. On the other hand, reliability and validity of the MATIES and SACIE-R have been demonstrated, with the MATIES, in particular, shown to be a well-validated questionnaire. Overall, the MATIES (Mahat, 2008) and SACIE-R (Forlin et al., 2011) appear to be the most psychometrically sound questionnaires that address each of the affective, cognitive and behavioural components of teacher attitudes towards inclusion. Where a focus on the cognitive and behavioural components would be sufficient, the TAIS can also be considered a sound scale given the current terminology, acceptable psychometrics, and completeness for addressing the cognitive and behavioural components of teacher attitudes.

\section{Supplementary Materials}

Requests for data used in this paper can be submitted, by email, to the first author. 


\section{Funding details}

This research did not receive any specific grant from funding agencies in the public, commercial, or not-for-profit sectors.

\section{Disclosure statement}

No potential conflict of interest was reported by the authors. 


\section{References}

Antonak, R. F., \& Larrivee, B. (1995). Psychometric analysis and revision of the opinions relative to mainstreaming scale. Exceptional Children, 62(2), 139-149. Retrieved from http://search.proquest.com/docview/618919395?accountid=14182

Antonak, R. F., \& Livneh, H. (2000). Measurement of attitudes towards persons with disabilities. Disability and Rehabilitation, 22(5), 211-224. http://doi.org/10.1080/096382800296782

Artiles, A. J., Kozleski, E. B., Dorn, S., \& Christensen, C. (2006). Learning in Inclusive Education Research: Re-mediating Theory and Methods With a Transformative Agenda. Review of Research in Education, 30(1), 65-108. http://doi.org/10.3102/0091732X030001065

Bailey, J. (2004). The validation of a scale to measure school principals' attitudes toward the inclusion of students with disabilities in regular schools. Australian Psychologist, 39(1), 76-87. Retrieved from http://search.proquest.com/docview/57164708?accountid=14182

de Boer, A., Timmerman, M., Pijl, S. J., \& Minnaert, A. (2012). The psychometric evaluation of a questionnaire to measure attitudes towards inclusive education. European Journal of Psychology of Education, 27(4), 573-589. http://doi.org/http://dx.doi.org/10.1007/s10212-011-0096-z

Department for Children Schools and Families. (2010). Evaluation of impact of DCSF investment in initiatives designed to improve teacher workforce skills in relation to SEN and disabilities: The first 6 months. London.

Department for Education. (2017). Permanent and fixed period exclusions from schools in England: 2015 to 2016. London. Retrieved from https://www.gov.uk/government/publications/permanent-and-fixed-period-exclusionsfrom-schools-in-england-2011-to-2012-academic-year

Department for Education and Skills. (2001). Inclusive schooling: Children with special educational needs. Nottingham.

Department for Education and Skills. (2003). Every child matters. London.

Department for Education and Skills. (2004). Inclusion and pupil achievement. Nottingham.

Department for Education and Skills. (2006). Preventing social exclusion of disabled children and their families. Nottingham.

Fitzpatrick, R., Davey, C., Buxton, M. J., \& Jones, D. R. (1998). Evaluating patient-based outcome measures for use in clinical trials. Health Technology Assessment, 2(14). Retrieved from http://www.ncbi.nlm.nih.gov/pubmed/9812244

Forlin, C., Earle, C., Loreman, T., \& Sharma, U. (2011). The Sentiments, Attitudes, and Concerns about Inclusive Education Revised (SACIE-R) scale for measuring pre-service teachers' perceptions about inclusion. Exceptionality Education International, 21(2-3), 50-65. Retrieved from http://search.proquest.com/docview/916527873?accountid=14182

Forlin, C., Keen, M., \& Barrett, E. (2008). The Concerns of Mainstream Teachers: Coping with inclusivity in an Australian context. International Journal of Disability, Development and Education, 55(3), 251-264. 
http://doi.org/10.1080/10349120802268396

Gibb, K., Tunbridge, D., Chua, A., \& Frederickson, N. (2007). Pathways to inclusion: Moving from special school to mainstream. Educational Psychology in Practice, 23(2), 109-127. http://doi.org/10.1080/02667360701320770

Goodman, R. L., \& Burton, D. M. (2010). The inclusion of students with BESD in mainstream schools: teachers' experiences of and recommendations for creating a successful inclusive environment. Emotional and Behavioural Difficulties, 15(3), 223 237. http://doi.org/10.1080/13632752.2010.497662

Grieve, A. M. (2009). Teachers' beliefs about inappropriate behaviour: Challenging attitudes? Journal of Research in Special Educational Needs, 9(3), 173-179. http://doi.org/10.1111/j.1471-3802.2009.01130.x

Hastings, R. P., \& Oakford, S. (2003). Student teachers' attitudes towards the inclusion of children with special needs. Educational Psychology, 23(1), 87-94.

http://doi.org/http://dx.doi.org/10.1080/01443410303223

Janney, R. E., \& Snell, M. E. (2006). Modifying schoolwork in inclusive classrooms. Theory Into Practice, 45(3), 215-223. http://doi.org/10.1207/s15430421tip4503

Larrivee, B., \& Cook, L. (1979). Mainstreaming: a Study of the Variables Affecting Teacher Attitude. The Journal of Special Education, 13(3), 315-324. http://doi.org/10.1177/002246697901300310

MacFarlane, K., \& Woolfson, L. M. (2013). Teacher attitudes and behavior toward the inclusion of children with social, emotional and behavioral difficulties in mainstream schools: An application of the theory of planned behavior. Teaching and Teacher Education, 29, 46-52. Retrieved from http://search.proquest.com/docview/1430186848?accountid=14182

Mahat, M. (2008). The development of a psychometrically-sound instrument to measure teachers' multidimensional attitudes toward inclusive education. International Journal of Special Education, 23(1), 82-92.

Monsen, J. J., Ewing, D. L., \& Boyle, J. (2015). Psychometric Properties of the Revised Teachers' Attitude Toward Inclusion Scale. International Journal of School \& Educational Psychology. http://doi.org/10.1080/21683603.2014.938383

Monsen, J. J., Ewing, D. L., \& Kwoka, M. (2014). Teachers' attitudes towards inclusion, perceived adequacy of support and classroom learning environment. Learning Environments Research, 17(1), 113-126. http://doi.org/10.1007/s10984-013-9144-8

Monsen, J. J., \& Frederickson, N. (2004). Teachers' Attitudes Towards Mainstreaming And Their Pupils' Perceptions of Their Classroom Learning Environment. Learning Environments Research, 7, 129-142.

Nowicki, E. A., \& Sandieson, R. (2002). A Meta-Analysis of School-Age Children's Attitudes Towards Persons with Physical or Intellectual Disabilities. International Journal of Disability, Development and Education, 49(3), 243-265. http://doi.org/10.1080/1034912022000007270

Pinney, A. (2016). Understanding the needs of disabled children with complex needs or lifelimiting conditions: What can we learn from national data? Council for Disabled Children and the True Colours Trust. 
Polat, F. (2011). Inclusion in education: A step towards social justice. International Journal of Educational Development, 31, 50-58. http://doi.org/10.1016/j.ijedudev.2010.06.009

Sharma, U., \& Desai, I. (2002). Measuring concerns about integrated education in India. Asia and Pacific Journal on Disability, 5(1), 2-14.

UNESCO. (1994). The Salamanca statement and framework for action on special needs education. Paris.

Wilczenski, F. L. (1995). Development of a scale to measure attitudes toward inclusive education. Educational and Psychological Measurement, 55(2), 291-299.

http://doi.org/http://dx.doi.org/10.1177/0013164495055002013 